\title{
Mycotoxin production of Alternaria strains isolated from Korean barley grains determined by LC-MS/MS
}

\author{
Thuong T.T. Nguyen ${ }^{a, 1}$, Jueun Kim ${ }^{b, 1}$, Sun Jeong Jeon ${ }^{a}$, Chul Won Lee ${ }^{b}$, Naresh Magan ${ }^{c}$, \\ Hyang Burm Lee ${ }^{\mathrm{a} * *}$
}

${ }^{a}$ Division of Food Technology, Biotechnology \& Agrochemistry, College of Agriculture \& Life Sciences, Chonnam National University, Gwangju 61186, South Korea

${ }^{b}$ Department of Chemistry, Chonnam National University, Gwangju 61186, South Korea

${ }^{c}$ Applied Mycology Group, Cranfield University, Cranfield, Bedford MK43 OAL, U.K.

*Corresponding author; e-mail: hblee@jnu.ac.kr
${ }^{1}$ These authors contributed equally to this work

Running title: Determination of Alternaria mycotoxins using LC-MS/MS

\begin{abstract}
Twenty-four Alternaria strains were isolated from barley grain samples. These strains were screened for the production of mycotoxins on rice medium using thin layer chromatography. All 24 strains produced at least one of the five mycotoxins (ALT, AOH, ATX-I, AME, and TeA). Three representative strains, namely EML-BLDF1-4, EML-BLDF1-14, and EMLBLDF1-18, were further analyzed using a new LC-MS/MS-based mycotoxin quantification method. This method was used to detect and quantify Alternaria mycotoxins. We used positive ion electrospray mass spectrometry with multiple reaction mode (MRM) for the simultaneous quantification of various Alternaria mycotoxins produced by these strains. Five Alternaria toxins (ALT, ATX-I, AOH, AME, and TeA) were detected and quantified. Sample preparation included methanol extraction, concentration, and injection into LC-MS/MS. Limit of detection ranged from 0.13 to $4 \mu \mathrm{g} / \mathrm{mL}$ and limit of quantification ranged from 0.25 to $8 \mu \mathrm{g} / \mathrm{mL}$.
\end{abstract}

Keywords: Alternaria mycotoxins; Alternaria strains; simultaneous quantification; determination; analysis conditions; LC-MS/MS

\section{Introduction}

Genus Alternaria comprises some of the most common plant pathogenic and saprophytic fungi that cause pre- and postharvest damage to agricultural products, including cereal grains, fruits, and vegetables (Ostry, 2008; Storm et al., 2014). The genus includes more than 300 species (Lee et al., 2015). Alternaria species produce various secondary metabolites. Some of these metabolites are known to be toxic, while others have not yet been studied and may be potentially toxic. The most common Alternaria toxins found in cereals and food items are alternariol (AOH), alternariol monomethyl ether (AME), tentoxin (TEN), altenuene (ALT), and tenuazonic acid (TeA) (López et al.,2014; Ostry, 2008; Patriarca et al., 2008). These toxins are classified into three different structural groups: (1) dibenzopyrone derivatives (AOH, AME, and ALT); (2) perylene-derived altertoxins (ATX-I, ATX-II, and ATX III); and (3) tetramic acid derivatives (TeA) (Pinto and Patriarca, 2017). Cereals can be infected by several species of genus Alternaria, particularly by A. alternata (Broggi et al., 2007; Azcarate et al., 2008; Xu et al., 2016). A. alternata synthesizes several mycotoxins such as AOH, AME, 
ALT, TeA, and ATX-I, which are the most frequently detected mycotoxins (Schade and King, 1984; Scott, 2001) (Fig. 1). These Alternaria mycotoxins are potential food contaminants and are found to be associated with agricultural products in nature.

Strong evidence suggests that AOH and AME may be mutagenic (An et al., 1989; Brugger et al., 2006). AOH and AME inhibit the secretion of progesterone by porcine granulosa cells in vitro. It has been reported that in vivo inhibition of progesterone production markedly affected reproductive performance in pigs and other mammals (Tiemann et al., 2009).

TeA is known to have acute toxic effects on human and animal health. It inhibits protein biosynthesis by ribosomes (Zhou and Qiang, 2008). It also shows several bioactivities, including antitumor, antibacterial, antiviral, and phytotoxic activities (Chelkowski and Visconti, 1992).

Altertoxins are responsible for causing acute toxicity in mice. They also cause mutagenicity and cytotoxicity in bacterial and mammalian cells (Solfrizzo et al., 2005).

Although these mycotoxins have a widespread occurrence, currently, there are no regulations governing Alternaria toxins in food and feed worldwide.

In a previous study, Lee and Yu showed that eight Alternaria species, namely $A$. cucumerina, A. dauci, A. macrospora, A. porri, A. sesami, A. solani, A. tagetica, and A. zinnia, that were isolated from red pepper fruits and sesame seeds in Korea produced AOH and AME (Lee and Yu, 1995a, 1995b). They also showed that potential mycotoxin-associated problems may exist in some agricultural products contaminated with Alternaria species, which produced large amounts of TeA, AOH, and AME. Their study demonstrated that 75 out of 280 isolates produced at least one of the five toxins, only A. alternata was toxic to rats, while the species, namely A. sesami, A. sesamicola, and A. solani, were nontoxic.

Therefore, Alternaria toxins have been receiving increasing attention in recent research, especially risk assessment studies. Accurate and rapid quantitative methods to measure Alternaria toxins would be very helpful for such studies. Recently, LC-MS/MS has been used to determine and confirm the presence of $\mathrm{AOH}$ and $\mathrm{AME}$ in apple juice and other fruit beverages at sub-nanogram per milliliter levels (Lau et al., 2003; Scussel et al., 2012). A multiphase method was developed by which 33 mycotoxins (including $\mathrm{AOH}$ and AME) in various products such as peanuts, pistachios, wheat, maize, cornflakes, raisins, and figs could be analyzed simultaneously (Lee et al., 2015). Although numerous mycotoxins have already been chemically characterized and classified in several studies, there are no data on Alternaria mycotoxins from Korean foodstuffs, which is a concern that needs to be addressed.

The purpose of this study was to develop a new quantitative method based on high performance liquid chromatography (HPLC)-tandem mass spectrometry (LC-MS/MS) for the detection and quantification of mycotoxins produced by Alternaria species isolated from Korean barley grain samples. The method established in this study was validated on 3 representative Alternaria strains producing mycotoxins.

\section{Materials and methods}

\subsection{Isolation of Alternaria strains from Korean barley grain samples}

Seeds of barley were collected from local growing areas of Jeonnam, Korea. A total of 100 barley seeds were placed in plates containing two layers of moist blotting paper, 20-25 seeds per plate. The plates were incubated at $25{ }^{\circ} \mathrm{C}$ for 7 days. Fungal spores on the seeds were examined under stereo microscope and transferred to potato dextrose agar (PDA) plates using 
a capillary tube. Pure isolates were maintained in PDA slant tubes and stored in $20 \%(\mathrm{v} / \mathrm{v})$ glycerol at $-80{ }^{\circ} \mathrm{C}$ at the Environmental Microbiology Laboratory Fungarium, Chonnam National University, Gwangju, Korea.

\subsection{Molecular identification of fungi}

Fungal strains were grown for $5-7$ days at $25{ }^{\circ} \mathrm{C}$ on PDA plates covered with cellophane. Genomic DNA was extracted from $50 \mathrm{mg}$ fungal mycelia of each isolate using the HiGene Genomic DNA Prep kit (BIOFACT Corp., Daejeon, Korea). The internal transcribed spacer (ITS) region, glyceraldehyde-3-phosphate dehydrogenase (gapdh), and RNA polymerase II subunit 2 (rpb2) genes were amplified with the primer pairs ITS4, ITS5 (White et al., 1990); gpd1, gpd2 (Berbee et al., 1999); and rpb2-5F-Eur, rpb2-7cr-Eur (Hibbett, 2006; Houbraken et al., 2011), respectively. The PCR amplification mixture (total volume, $20 \mu \mathrm{L}$ ) contained $2 \mu \mathrm{L}$ DNA template, $1.5 \mu \mathrm{L}$ each primer $(5 \mathrm{pM}), 14 \mu \mathrm{L}$ demineralized sterile water, and $1 \mu \mathrm{L}$ Accuprep PCR Premix (containing Taq DNA polymerase, dNTPs, buffer, and a tracking dye; Bioneer Corp., Daejeon, Korea). PCR products were purified using the Accuprep PCR Purification kit (Bioneer Corp.) according to the manufacturer's instructions. DNA sequencing was performed on an ABI 3700 Automated DNA sequencer (Applied Biosystems Inc., Foster City, CA, USA).

Sequence data obtained from the GenBank database (Table 1) were aligned using ClustalX v.1.83 (Thompson et al., 1997) and edited with Bioedit v.5.0.9.1 (Hall, 1999). Phylogenetic analyses were performed using MEGA 6 (Tamura et al., 2013). The neighbor joining (NJ) and maximum likelihood (ML) phylogenetic trees were constructed for individual datasets for ITS rDNA and combined datasets of the ITS, gapdh, and rpb2 sequences. The sequences of Dendryphiella salina, Cochliobolus heterostrophus, and Alternaria alternantherae were used as outgroups.

\subsection{Production and extraction of Alternaria mycotoxins}

For inoculum preparation, $50 \mathrm{~g}$ rice grains were placed in 500-mL Erlenmeyer flasks containing $50 \mathrm{~mL}$ distilled water. The flasks containing the media were autoclaved at $121{ }^{\circ} \mathrm{C}$ for $30 \mathrm{~min}$, and allowed to stand overnight. Each flask was inoculated with mycelial plugs obtained from a 7-day-old PDA culture and incubated at $25{ }^{\circ} \mathrm{C}$ for 2 weeks. The flasks were shaken once or twice daily, during the initial $2 \mathrm{~d}$ to ensure growth of fungal mycelia on rice grains. After 2 weeks, alternaria toxins were extracted from rice grains as described previously by Lee and Yu (Lee and Yu, 1995b). Briefly, $50 \mathrm{~g}$ rice grains were extracted with $250 \mathrm{~mL}$ methanol and filtered through a filter paper (Whatman No 2). The filtrate was clarified with $80 \mathrm{~mL} 20 \%$ ammonium sulfate, partitioned into methylene chloride, and divided into two parts. The organic phase was combined and the solvent was completely evaporated. $1 \mathrm{~mL}$ methanol was added to dissolve the residues. ALT, AOH, AME, and ATX-I were analyzed by TLC.

For TeA analysis, the water phase remaining after methylene chloride extraction was adjusted to $\mathrm{pH} 2$ with $6 \mathrm{~N} \mathrm{HCl}$ and extracted twice with $50 \mathrm{~mL}$ methylene chloride. Next, TeA was partitioned using $30 \mathrm{~mL} \mathrm{5 \%}$ sodium bicarbonate that was subsequently acidified to $\mathrm{pH} 2$, and extracted twice with $2 \mathrm{~mL}$ methylene chloride. The methylene extracts were combined and evaporated to dryness. The residue was redissolved in methanol and TeA analysis was performed using TLC. 


\subsection{Thin layer chromatography (TLC) analysis}

TLC was performed as described previously by Lee and Yu (1995ab). Briefly, $2 \mu \mathrm{L}$ solvent extract was spotted onto $10 \times 10 \mathrm{~cm}$ silica gel plates (Kiesel gel 60 F254; Merck, Darmstadt, Germany) precoated with fluorescen indicator for TLC separation. Subsequently, the TLC plates were developed in a glass chamber using $100 \mathrm{~mL}$ mobile phase containing a mixture of chloroform:acetone $(88: 12, \mathrm{v} / \mathrm{v})$. The plate was removed from the chamber and air-dried. Mycotoxins were detected under UV light at 254 and $365 \mathrm{~nm}$ (Vilber Lourmat, Marne La ValleBe, France).

\section{5. $L C-M S / M S$ analysis}

This method was developed using the Shimadzu LC-10ADvp system (Shimadzu, Japan) coupled to the API2000 (AB SCIEX, US) with a triple quadrupole. The Thermo Scientific BDS Hypersil C8 column $(3 \times 50 \mathrm{~mm}, 3-\mu \mathrm{m}$ particle size; US $)$ was used. The column temperature was set at $25{ }^{\circ} \mathrm{C}$. The mobile phases were water (Milli-Q) containing $2 \mathrm{mM}$ ammonium formate with $0.1 \%$ formic acid (mobile A) and acetonitrile with $0.1 \%$ formic acid (mobile B) at a flow rate of $0.4 \mathrm{~mL} / \mathrm{min}$. Acetonitrile (ACN, LC gradient grade) was purchased from Merck (Darmstardt, Germany), and formic acid (LC-MS grade) and ammonium formate $\left(\right.$ Optima $^{\circledR}$ LC-MS grade) were obtained from Sigma-Aldrich and Thermo Scientific, respectively. B was held at 3\% from 0 to $1 \mathrm{~min}$, increased to $95 \%$ for 13 min, and brought back to $3 \%$ within $1 \mathrm{~min}$. The system was equilibrated for $15 \mathrm{~min}$ at $3 \% \mathrm{~B}$ before the next run. Analytical grade calibrants for ALT, ATX-I, TeA, AOH, and AME were purchased from Sigma-Aldrich. Stock solutions were prepared by diluting with $100 \%$ methanol containing $0.1 \%$ formic acid. All stock solutions were stored in a refrigerator at -20 ${ }^{\circ} \mathrm{C}$ until further use. The extracts from EML-BLDF1-4 (2.3 mg), EML-BLDF1-14 (3.0 mg), and EML-BLDF1-18 (3.0 mg) were re-dissolved in $200 \mu \mathrm{L}$ methanol containing $0.1 \%$ formic acid and injected in LC-MS/MS. The injection volume was $5 \mu \mathrm{L}$. The mass spectrometer was operated in the ESI positive ionization mode using multiple reaction monitoring (MRM) mode. Two ion transitions (Q1 and Q3) were scanned for each target toxin. The selected ion transitions were optimized with respect to declustering potential (DP), focusing potential (FP), entrance potential (EP), collision cell entrance potential (CEP), collision energy (CE), and collision cell exit potential (CXP). The optimized mass spectrometry parameters were as follows: curtain gas, 30; spray voltage, 5,500; source temperature, $500{ }^{\circ} \mathrm{C}$; and ion source gas, 50 psi.

\subsection{Method validation}

The analysis method was validated for EML-BLDF culture medium samples using LCMS/MS system. The calibration curve was constructed over a concentration range of $0.25-$ $256 \mu \mathrm{g} / \mathrm{mL}$. Four different points were plotted. The limit of detection (LOD) and limit of quantification (LOQ) of the method were calculated as 3 and $10 \times$ signal-to-noise ratio, respectively. The coefficient of correlation $\left(\mathrm{R}^{2}\right)$ was used to judge the linearity. Recovery rates were determined by adding $100 \mu \mathrm{L}$ standard mixture to the sample before extraction, amounting to LOQ1 and LOQ2 of each toxin. 


\section{Results and discussion}

\subsection{Identification of fungi}

Results of the ITS rDNA sequence analysis of 24 isolates from barley samples are shown in Fig. 2. 24 isolates were placed within section Alternaria as described by Woudenberg et al. (2013). BLASTn search revealed that the ITS sequences of isolates showed $99.4 \%-100 \%$ to those of Alternaria alternata.

Within section Alternaria, three representative strains, namely EML-BLDF1-4, EML-BLDF1-14, and EML-BLDF1-18, were identified based on two additional genes, gapdh and $r p b 2$. BLASTn results revealed that the gapdh gene sequences of EML-BLDF1-4, EML-BLDF1-14, and EML-BLDF1-18 showed 100\% (562/562, 564/564, and 574/574 bp, respectively) identity with those of $A$. alternata (GenBank accession no. KP057228), $A$. tenuissima (GenBank accession no. KY290574), and A. alternata (GenBank accession no. KP057228), respectively. The $r p b 2$ gene sequences of strains EML-BLDF1-4, EML-BLDF114, and EML-BLDF1-18 showed 100\% (824/824, 865/865, and 865/865 bp) identity with those of A. tenuissima (GenBank accession no. LT707523), A. alternata (GenBank accession no. KU738707), and A. alternata (GenBank accession no. KU738707), respectively. Phylogenetic analyses based on the combined dataset of ITS, gapdh, and rpb2 sequences showed that the strains EML-BLDF1-4, BLDF1-14, and BLDF1-18 were placed within the $A$. alternata clade of sect. Alternaria (Woudenberg et al., 2015) (Fig. 3).

Our results showed that 24 strains from barley grains were identified as Alternaria alternata. Bruce et al. (1984) observed Alternaria infection in all 57 barley samples analyzed, and identified A. alternata as the dominant species. Sanchis et al. (1993) also reported that the most predominant genera were Alternaria, Penicillium, and Aspergillus, which were isolated from 60 samples of barley collected in Spain. Most Alternaria isolates were identified as A. alternata (90.2\%). A recent study by Medina et al. (2006) showed that Alternaria species were the dominant fungal species isolated from malting barley samples.

\subsection{TLC analysis}

Solvent extracts of the 24 strains of A. alternata isolated from barley samples were developed on TLC plates for the detection of mycotoxins (Table 2). TLC analyses showed that all the 24 strains were able to produce at least one of the five mycotoxins in rice culture medium. 24 strains $(100 \%)$ produced both ALT and AOH, 18 strains $(75 \%)$ produced ATX-I, 22 strains (91.6\%) produced AME, and 9 strains (37.5\%) produced TeA (Fig. 4). Thus, we demonstrated and confirmed the presence of five mycotoxins, including ALT, AOH, AME, TeA, and ATX-I, using TLC analysis. AME, ALT, ATX-I, and TeA were identified on the basis of their $R f$ values using the TLC system constructed by Lee et al. (1995ab). AOH, AME, and TeA were also detected in rice culture medium (Mass et al.,1981; Bruce et al., 1984; Torres et al., 1998; Medina et al., 2006).

After TLC analysis, three Alternaria strains, namely EML-BLDF1-4, EML-BLDF1-14, EML-BLDF1-18, were selected for further analyses with optimization of LC-MS/MS conditions based on the ability to produce different mycotoxins. In the present study, EMLBLDF1-18, EML-BLDF1-4, EML-BLDF1-14 were assigned as TeA, ATX-I, and AOH and AME producing strains, respectively.

\subsection{Optimization of $L C-M S / M S$ conditions}


LC-MS/MS analysis with multiple reaction monitoring (MRM) mode enables sensitive and specific detection of target toxins. MS/MS settings were optimized on the API2000 instrument using direct infusion of individual standard solutions and flow injection analysis. Ion transitions were tuned using $10 \mu \mathrm{g} / \mathrm{mL}$ standard solutions in $100 \%$ methanol containing $0.1 \%$ formic acid. MThe mass parameters were optimized to obtain the strongest signals for $[\mathrm{M}+\mathrm{H}]^{+}$ion. The product ion values were determined from the results of the MS/MS analysis. The optimized precursor and product ions are summarized in Table 3. Changing the ion trace selection resulted in decreased noise peaks and enhanced selectivity for appropriate identification. The mobile phase was chosen based on the ionization and separation efficiency. Due to good separation performance, ACN was employed as strong elution mobile phase B and water was chosen as weak elution mobile phase A. The Alternaria toxins were separated by gradient conditions for $14 \mathrm{~min}$ (Fig. 5).

\subsection{Method validation}

The calibration equation, $\mathrm{R}^{2}$, LOD, and LOQ values have been shown in Table 4. A linear calibration curve (concentration range, $0.25-256 \mu \mathrm{g} / \mathrm{mL}$ ) was obtained for all five Alternaria toxins. The $\mathrm{R}^{2}$ value ranged from 0.993 to 0.999 . The LOD value ranged from $0.13 \mu \mathrm{g} / \mathrm{mL}$ for ALT to $4 \mu \mathrm{g} / \mathrm{mL}$ for ATX-I. The LOQ value ranged from $0.25 \mu \mathrm{g} / \mathrm{mL}$ for ALT to $8 \mu \mathrm{g} / \mathrm{mL}$ for ATX-I. These LOD and LOQ values were either similar or lower compared to those determined using LC-MS/MS in earlier studies (Meena et al., 2017; Prelle et al., 2013). Sample recovery calculated by external standard method using standard solutions for ALT, ATX-I, TeA, AOH, and AME ranged from 83.5 to $99.2 \%$ of their spiked concentrations. Precision of the method was determined by evaluating its reproducibility expressed in terms of RSD (\%). RSD ranged from 0.59 to $12.06 \%$ (Table 5).

\subsection{Analysis of Alternaria mycotoxins in EML-BLDF rice culture medium}

The culture media extracts of EML-BLDF were concentrated and re-dissolved in $100 \%$ methanol containing $0.1 \%$ formic acid and analyzed by LC-MS/MS. The toxigenic profiles of mycotoxins produced by three Alternaria strains EML-BLDF1-4, EML-BLDF1-14, and EML-BLDF1-18 on rice culture medium have been shown in Table 6. Our data showed that ALT was detected in the extracts from all three strains. The highest concentration of ALT was $85.5 \mu \mathrm{g} / \mathrm{mL}$ in the EML-BLDF1-4 extract. TeA was detected only in the EML-BLDF1-18 extract. Its concentration was higher $(201 \mu \mathrm{g} / \mathrm{mL})$ than that of the other mycotoxins. In addition, ATX-I was detected only in the EML-BLDF1-4 extract. Interestingly, the benzopyrone derivatives (AOH, AME, and ALT) were detected in both the EML-BLDF1-4 and EML-BLDF1-14 extracts.

In our study, compared to the other toxins detected in rice culture medium extracts, TeA concentration was observed to be the highest. Notably, high TeA concentration was also reported by other authors in earlier studies. Logrieco et al. (1990) showed that 14 strains $(100 \%)$ produced TeA and the concentration of this toxin was $6,000 \mathrm{mg} / \mathrm{kg} ; 13$ strains $(93 \%)$ produced AOH, AME, and ALT and the concentrations of these toxins were 120, 59, and 37 $\mathrm{mg} / \mathrm{kg}$, respectively. Li et al. (2001) observed that among the 25 isolates obtained from the Chinese weathered wheat, $8(32 \%)$ isolates produced TeA $(1,369-3,563 \mathrm{mg} / \mathrm{kg}), 25(100 \%)$ produced $\mathrm{AOH}(2-178 \mathrm{mg} / \mathrm{kg}), 25$ (100\%) produced AME (1-98 mg/kg), 21 (84\%) 
produced ALT (2-145 mg/kg), and 21 (84\%) produced ATX-I (2-23 mg/kg). Sanchis (1993) observed that among the $176 \mathrm{~A}$. alternata isolates obtained from barley collected in Spain, the percentage of species producing TeA, $\mathrm{AOH}$, and $\mathrm{AME}$ was $88.6 \%, 15.3 \%$, and 9\%, respectively. Similar data were obtained by Patriarca et al. (2007). They reported that the highest concentration of TeA (up to $9,478 \mathrm{mg} / \mathrm{kg}$ ) was observed in the A. alternata isolate from Argentinean wheat; however, $\mathrm{AOH}$ and AME were present at lower concentrations (4622 and $21-2,352 \mathrm{mg} / \mathrm{kg}$, respectively).

Results of the present study indicated that the amount of toxin produced by Alternaria isolates varied considerably among different isolates. Different growth conditions affected mycotoxin production, especially the production of TeA. Magan et al. (1984) and Sanchis and Magan (2004) showed that water activity played an important role in the production of $\mathrm{AE}$, AME, AOH, and TeA in A. alternata. Temperature is also an essential factor in growth of $A$. alternata on toxin synthetic medium (Pose et al., 2010). Brzonkalik et al. (2011) showed that carbon and nitrogen sources affected mycotoxin production by affecting A. alternata growth on synthetic medium.

Our study showed that A. alternata strains isolated from barley seed grains in Korea produced different mycotoxins on rice culture medium. Especially, the strain EML-BLDF118 produced high amounts of the TeA toxin. In addition, among all the strains, the strain EML- BLDF1-4 was the best producer.

In future, studies evaluating the natural occurrence of ALT, AOH, ATX-I, AME, and TeA on different grains, including barley, produced by A. alternata should be performed.

\section{Conclusion}

Mycotoxin production by 24 Alternaria strains isolated from Korean barley grains was analyzed. Herein, we developed and validated a reliable LC-MS/MS method for the simultaneous determination of various Alternaria mycotoxins. Our results showed that ALT, ATX-I, AOH, AME, and TeA were detected in the rice culture medium extracts ranging from $0.25-8,8-256,4-64,4-64$, and $6.25-100 \mu \mathrm{g} / \mathrm{mL}$, respectively.

\section{Acknowledgments}

This work was supported by a grant from the National Institute of Animal Science and from under Rural Development Administration, and in part by a fund from National Institute of Food and Drug Safety Evaluation under the Ministry of Food and Drug Safety, Republic of Korea.

\section{References}

An, Y.H., Zhao, T.Z., Miao, J., Liu, G.T, Zheng, Y.Z., Xu, Y.M., Van Etten, R.L., 1989. Isolation, identification, and mutagenicity of alternariol monomethyl ether. J. Agric. Food Chem. 37, 1341-1343.

Azcarate, M.P., Patriarca, A., Terminiello, L., Fernández Pinto, V., 2008. Alternaria toxins in wheat during the 2004 to 2005 Argentinean harvest. J. Food Prot. 71, 1262-1265.

Berbee, M.L., Pirseyedi, M., Hubbard, S., 1999. Cochliobolus phylogenetics and the origin of known, highly virulent pathogens, inferred from ITS and glyceraldehyde-3-phosphate dehydrogenase gene sequences. Mycologia. 91, 964-977.

Broggi, L.E., González, H.H.L., Resnik, S.L., Pacin, A.M., 2007. Alternaria alternata 
prevalence in cereal grains and soybean seeds from Entre Ríos, Argentina. Rev. Iberoam. Micol. 24, 47-51.

Bruce, V.R., Stack, M.E., Mislivec, P.B., 1984. Incidence of toxic Alternaria species in small grains from the USA. J. Food Sci. 49, 1626-1627.

Brzonkalik, K., Herrling, T., Syldatk, C., Neumann, A., The influence of different nitrogen and carbon sources on mycotoxin production in Alternaria alternata. Int. J. Food Microbiol. 147, 120-126.

Brugger, E.M., Wagner, J., Schumacher, D.M., Koch, K., Podlech, J., Metzler, M., Lehmann, L., 2006. Mutagenicity of the mycotoxin alternariol in cultured mammalian cells. Toxicol. Lett. 164, 221-230.

Chelkowski, J., Visconti, A., 1992. Alternaria: Biology, Plant Diseases and Metabolites. Amsterdam, The Netherlands: Elsevier, 449-541.

Hall, T.A., 1999. BioEdit: a user-friendly biological sequence alignment editor and analysis program for Windows 95/98/NT. Nucleic Acids Symp. Ser. 41, 95-8.

Hibbett, D.S., 2006. A phylogenetic overview of the Agaricomycotina. Mycologia. 98, 917925.

Houbraken, J., Frisvad, J.C., Samson, R.A., 2011. Taxonomy of Penicillium section Citrina. Stud. Mycol. 70, 53-138.

Lau, B.P.-Y, Scott, P.M., Lewis, D.A., Kanhere, S.R., Cléroux, C., Roscoe, V.A., 2003. Liquid chromatography-mass spectrometry and liquid chromatography-tandem mass spectrometry of the Altemaria mycotoxins alternariol and alternariol monomethyl, ether in fruit juices and beverages. J. Chromatogr. A. 998,119-131.

Lee, H.B., Patriarca, A., Magan, N., 2015. Alternaria in food: ecophysiology, mycotoxin production and toxicology. Mycobiology. 43, 93-106.

Lee, H.B., Yu, S.H., 1995a. Incidence of Alternaria species in red pepper and sesame from Korea and their ability to produce mycotoxins. Plant Pathol. J. 11, 1-8.

Lee, H.B., Yu, S.H., 1995b. Distribution of mycotoxin-producing isolates in the genus Alternaria. Plant Pathol. J. 11, 151-7.

Li, FQ., Toyazaki, N., Yoshizawa, T., 2001. Production of Alternaria mycotoxins by Alternaria alternata isolated from weather-damaged wheat. J. Food Prot. 64, 567-571.

Logrieco, A., Bottalico, A., Solfrizzo, M., Mule, G., 1990. Incidence of Alternaria species in grains from mediterranean countries and their ability to produce mycotoxins. Mycologia. 82, 501-505.

Magan, N., Cayley, G.R., Lacey, J., 1984. Effect of water activity and temperature on mycotoxin production by Alternaria alternata in culture and on wheat grain. Appl. Environ. Microbiol. 47, 1113-1117.

Mass M.R., Woody M.A., Chu F.S., 1981. Production of alternariol and alternariol methyl ether by Alternaria spp. J. Food Saf. 3, 39-47.

Medina, A., Valle-Algarra, F.M., Mateo, R., Gimeno-Adelantado, J.V., Mateo, F. and Jiménez, M., 2006. Survey of the mycobiota of Spanish malting barley and evaluation of the mycotoxin producing potential of species of Alternaria, Aspergillus and Fusarium. Int. J. Food Microbiol. 108, 196-203.

Meena, M., Swapnil, P., Upadhyay, R.S., 2017. Isolation, characterization and toxicological potential of Alternaria-mycotoxins (TeA, $\mathrm{AOH}$ and $\mathrm{AME}$ ) in different Alternaria species from various regions of India. Sci. Rep. 7, 8777.

López, P., Venema, D., de Rijk T, de Kok, A., Scholen, J., Mol, H., de Nijs, M., 2014. Occurrence of Alternaria mycotoxins in food products in the Netherlands. In: World 
Mycotoxin Forum, Vienna, Austria

Ostry, V., 2008. Alternaria mycotoxins: an overview of chemical characterization, producers, toxicity, analysis and occurrence in foodstuffs. World Mycotoxin J. 1, 175-188.

Patriarca, A., Azcarate, M.P., Terminiello, L., Pinto, V.F., 2007. Mycotoxin production by Alternaria strains isolated from Argentinean wheat. Int. J. Food Microbiol. 119, 219-222.

Pinto, V.E.F., Patriarca, A., 2017. Alternaria species and their associated mycotoxins. Methods Mol. Biol. 1542, 13-32.

Pose, G., Patriarca, A., Kyanko, V., Pardo, A., Fernández Pinto, V., 2010. Water activity and temperature effects on mycotoxin production by Alternaria alternata on a synthetic tomato medium. Int. J. Food Microbiol. 142, 348-353.

Prelle, A., Spadaro, D., Garibaldi, A., Gullino, M.L., 2013. A new method for detection of five alternaria toxins in food matrices based on LC-APCI-MS. Food Chem. 140, 161-167.

Schade, J.E., King, A.D.Jr., 1984. Analysis of the major Alternaria toxins. J. Food Protect. 47, 978-995.

Sanchis, V., Magan, N., 2004. Environmental profiles for growth and mycotoxin production. Chapter 8. In: Magan N, Olsen M, editors. Mycotoxins in food: detection and control. Cambridge: Woodhead Publishing Ltd.; 174-189.

Sanchis, V., Sanclementele, A., Usall, J., Vinas, I., 1993. Incidence of mycotoxigenic Alternaria alternata and A. flavus in barley. J. Fd. Prot. 56, 246-248.

Solfrizzo, M., Girolamo, A.D., Vitti, C., Tylkowska, K., Grabarkiewicz-Szczesna, J., Szopińska, D., Dorna, H., 2005. Toxigenic profile of Alternaria alternata and Alternaria radicina occurring on umbelliferous plants. Food Addit. Contam. 22, 302-308.

Scott, P.M., 2001. Analysis of agricultural commodities and foods for Alternaria mycotoxins. J. AOAC Int. 84, 1809-1817.

Scussel, V.M., Scholten, J.M., Rensen, P.M., Spanjer, M.C., Giordano, B.N.E., Savi, G.D., 2012. Multitoxin evaluation in fermented beverages and cork stoppers by liquid chromatography-tandem mass spectrometry. Int. J. Food Sci. Technol. 48, 96-102.

Storm, I.M.L.D., Rasmussen, R.R., Rasmussen, P.H., 2014. Occurrence of pre- and postharvest mycotoxins and other secondary metabolites in Danish maize silage. Toxins. 6, 22562269.

Tamura, K., Stecher, G., Peterson, D., Filipski, A., Kumar, S., 2013. MEGA6: molecular evolutionary Genetics analysis version 6.0. Mol. Biol. Evol. 30, 2725-2729.

Thompson, J.D., Gibson, T.J, Plewniak, F., Jeanmougin, F., Higgins, D.G., 1997. The CLUSTAL_X windows interface: flexible strategies for multiple sequence alignment aided by quality analysis tools. Nucleic Acids Res. 25, 4876-4882.

Tiemann, U., Tomek, W., Schneider, F., Müller, M., Pöhland, R., Vanselow, J., 2009. The mycotoxins alternariol and alternariol methyl ether negatively affect progesterone synthesis in porcine granulosa cells in vitro. Toxicol. Lett. 186, 139-145.

Torres, A., González, H.H., Etcheverry, M., Resnik, S.L., Chulze, S., 1998. Production of alternariol and alternariol mono-methyl ether by isolates of Alternaria spp. from Argentinian maize. Food Addit Contam. 15, 56-60.

White, T.J., Bruns, T., Lee, S., Taylor, J., 1990. Amplification and direct sequencing of fungal ribosomal RNA genes for phylogenetics. In: Innis MA, Gelfand DH, Sninsky JJ, White TJ, editors. PCR protocols: Academic Press. pp. 315-322.

Woudenberg, J.H.C., Groenewald, J.Z., Binder, M., Crous, P.W., 2013. Alternaria redefined. Stud. Mycol. 75, 171-212.

Woudenberg, J.H.C., Seidl, M.F., Groenewald, J.Z., de Vries, M., Stielow, J.B., Thomma, 
B.P.H.J., Crous, P.W., 2015. Alternaria section Alternaria: Species, formae speciales or pathotypes? Stud. Mycol. 82, 1-21.

Xu, W., Han, X., Li, F., Zhang, L., 2016. Natural occurrence of Alternaria toxins in the 2015 wheat from Anhui province, China. Toxins. 8, 308.

Zhou, B., Qiang, S., 2008. Environmental, genetic and cellular toxicity of tenuazonic acid isolated from Alternaria alternata. Afr. J. Biotechnol. 7, 1151-1156.

\section{Figure legends}

Fig. 1. Chemical structures of Alternaria mycotoxins: (A) ALT; (B) ATX-I; (C) AOH; (D) AME; and (E) TeA.<smiles>COc1cc(O)c2c(c1)C1=C[C@H](O)C(O)CC1(C)OC2=O</smiles>

(B)<smiles>O=C1C[C@H](O)[C@@H]2c3c(ccc(O)c31)-c1ccc(O)c3c1[C@@]2(O)CCC3=O</smiles>

(D)<smiles>COc1cc(O)c2c(=O)oc3cc(O)cc(C)c3c2c1</smiles>

(E)<smiles>CC[C@H](C)[C@H]1NC(=O)C(C(C)=O)=C1O</smiles><smiles>Cc1cc(O)cc2oc(=O)c3c(O)cc(O)cc3c12</smiles>

Fig. 2. Phylogenetic tree constructed based on the ITS rDNA sequences using neighborjoining method. The sequences of Dendryphiella salina and Cochliobolus heterostrophus were selected as the outgroups. Numbers at the nodes indicate the bootstrap values (> 50\%) of 1,000 replicates. 


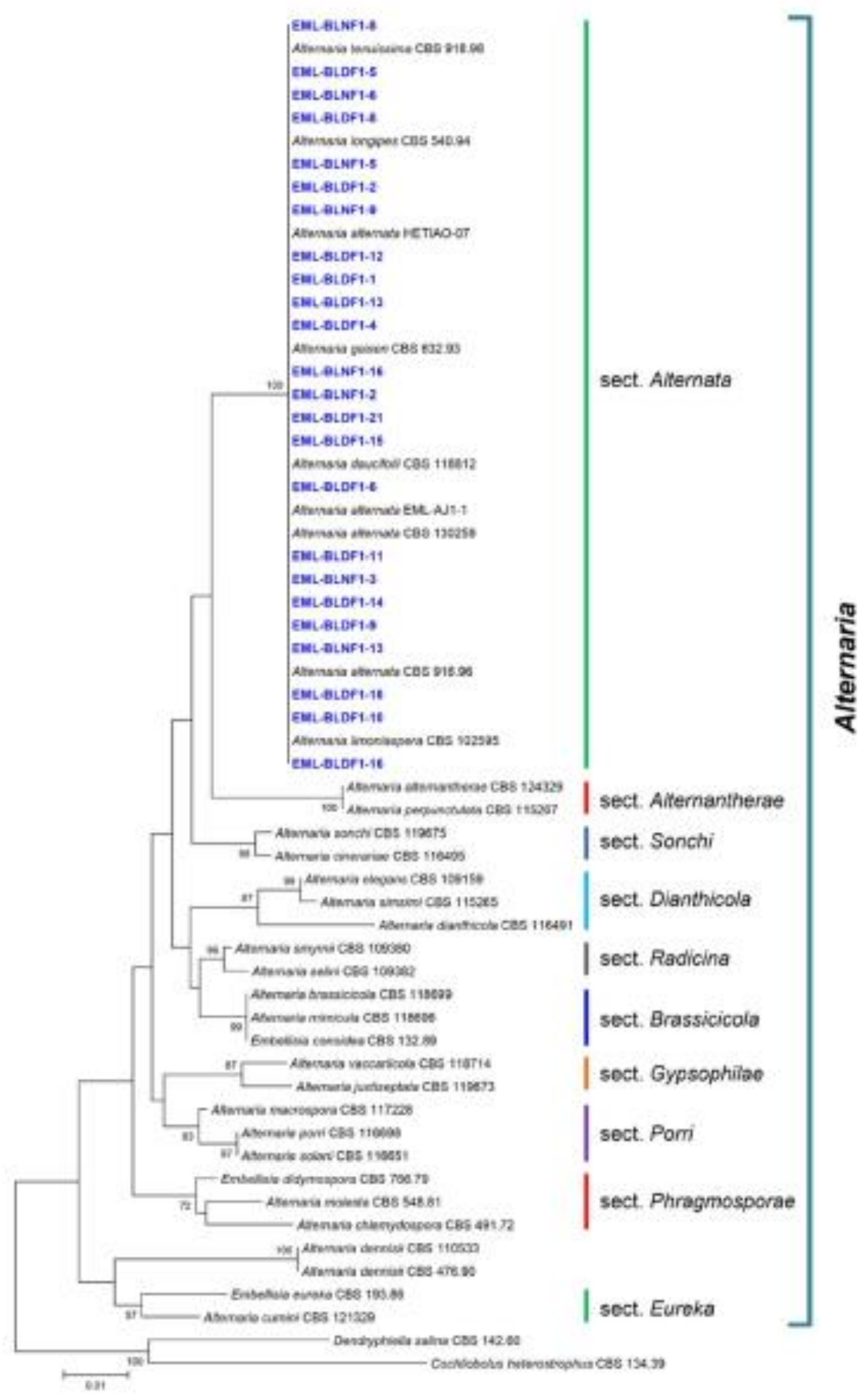

Fig. 3. Phylogenetic tree constructed based on the combined datasets of the internal transcribed spacer (ITS), glyceraldehyde-3-phosphate dehydrogenase ( $g a p d h$ ), and $r p b 2$ gene sequences using maximum likelihood method. The sequence of Alternaria alternantherae CBS 124392 was selected as the outgroup. Numbers at the nodes indicate the bootstrap 
values $(>50 \%)$ from 1,000 replications.

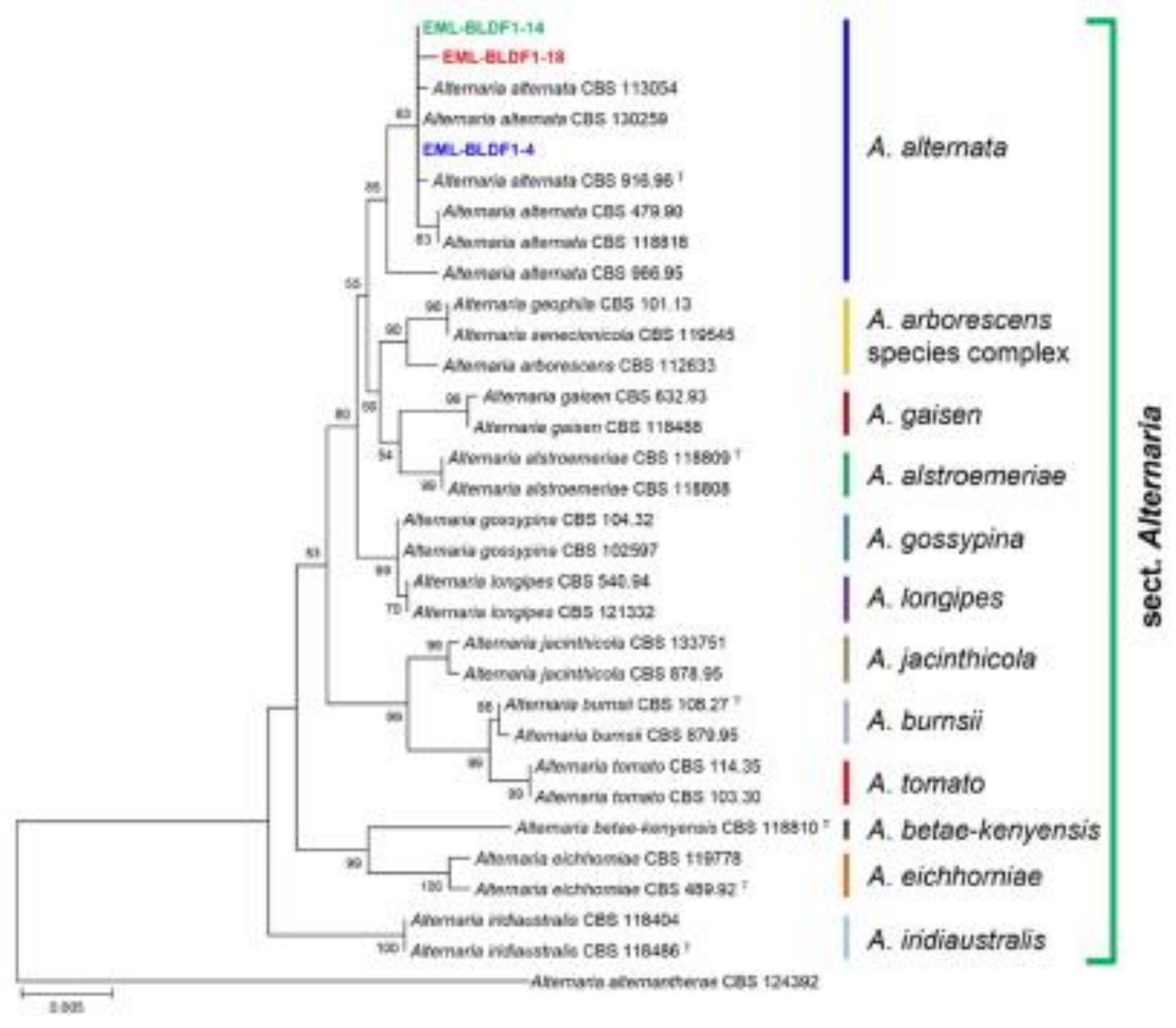

Fig. 4. Thin layer chromatography (TLC) analysis of Alternaria mycotoxins produced by different Alternaria strains. Different spots of Alternaria culture extracts on TLC plates under $254 \mathrm{~nm}$ UV (A) and $365 \mathrm{~nm}$ UV (B). 1-14 Sample (1, EML-BLDF1-1; 2, EML-BLDF1-1; 3, EML-BLDF1-4; 4, EML-BLDF1-5; 5, EML-BLDF1-6; 6, EML-BLDF1-8; 7, EML-BLDF1- 
9; 8, EML-BLDF1-10; 9, EML-BLDF1-11; 10, EML-BLDF1-12; 11, EML-BLDF1-13; 12, EML-BLDF1-14; 13, EML-BLDF1-15; 14, EML-BLDF1-16; 15, EML-BLDF1-18; 16, EML-BLDF1-21; 17, EML-BLNF1-2; 18, EML-BLNF1-3; 19, EML-BLNF1-5; 20, EMLBLNF1-6; 21, EML-BLNF1-8; 22, EML-BLNF1-9; 23, EML-BLNF1-13; and 24, EMLBLNF1-16. TLCs on silica gel plates (Kiesel gel 60 F254) were developed in chloroform:acetone $(88: 12, \mathrm{v} / \mathrm{v})$, air-dried, and then irradiated under short and long UV wavelength.

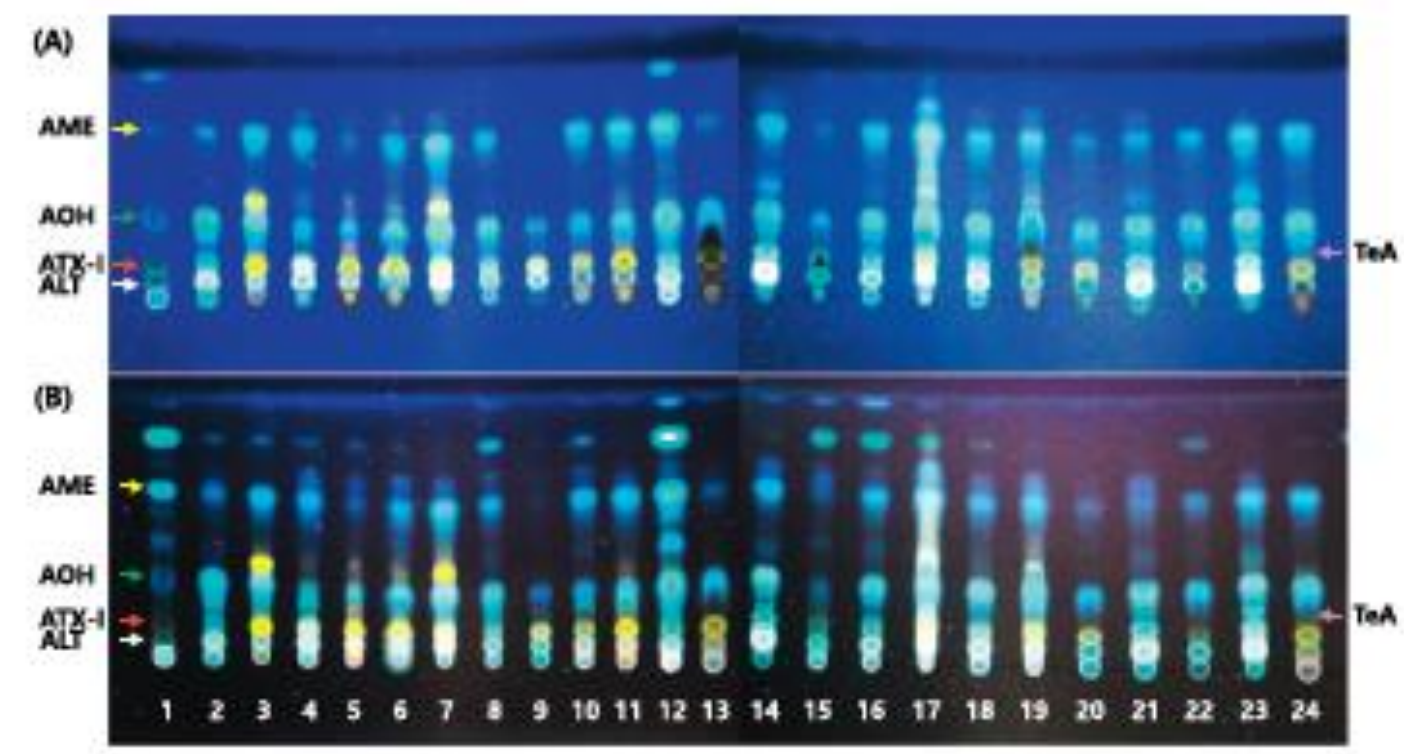

Fig. 5. Multiple reaction monitoring (MRM) chromatogram for selective ion chromatogram: (A) ALT, (B) ATX-I, (C) AOH, and (D) AME obtained from the culture of strain EMLBLDF1-4; (E) ALT, (F) AOH, and (G) AME obtained from the culture of strain EMLBLDF1-14; (H) TeA, and (I) ALT obtained from the culture of strain EML-BLDF1-18. 

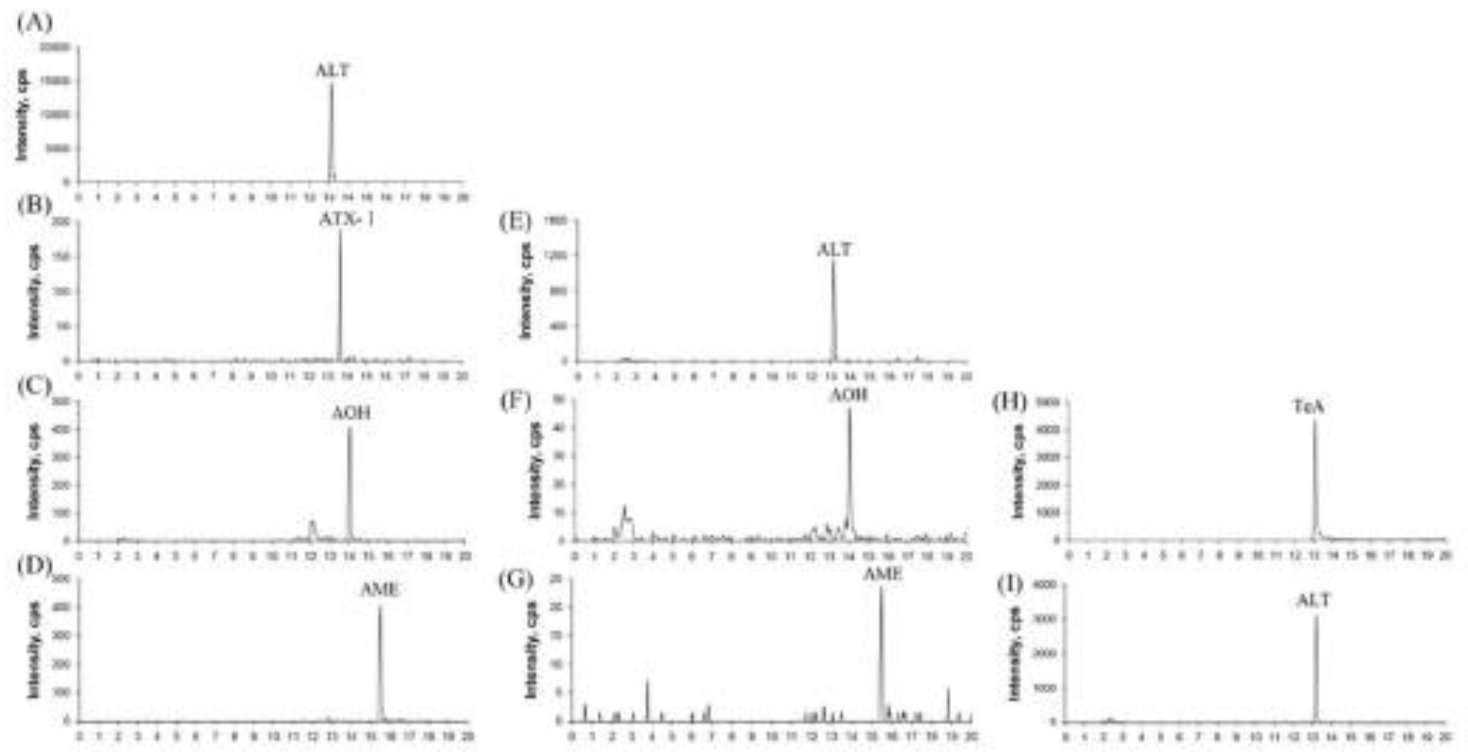

Fig. 6. Standard calibration curves for Alternaria mycotoxins: ALT, ATX-I, TeA, AOH, AME.
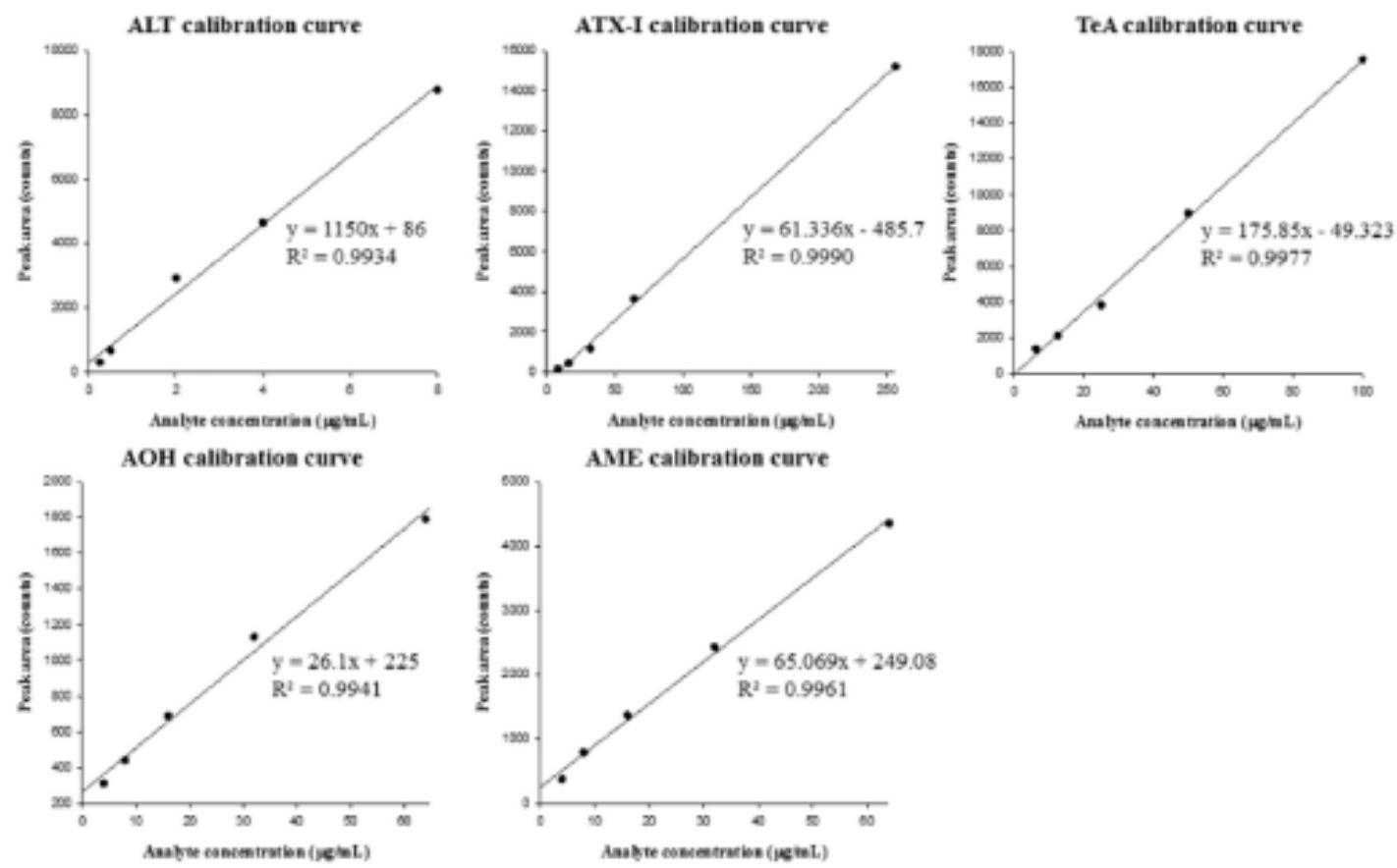
Table 1

Sequences used in this study, including GenBank accession numbers.

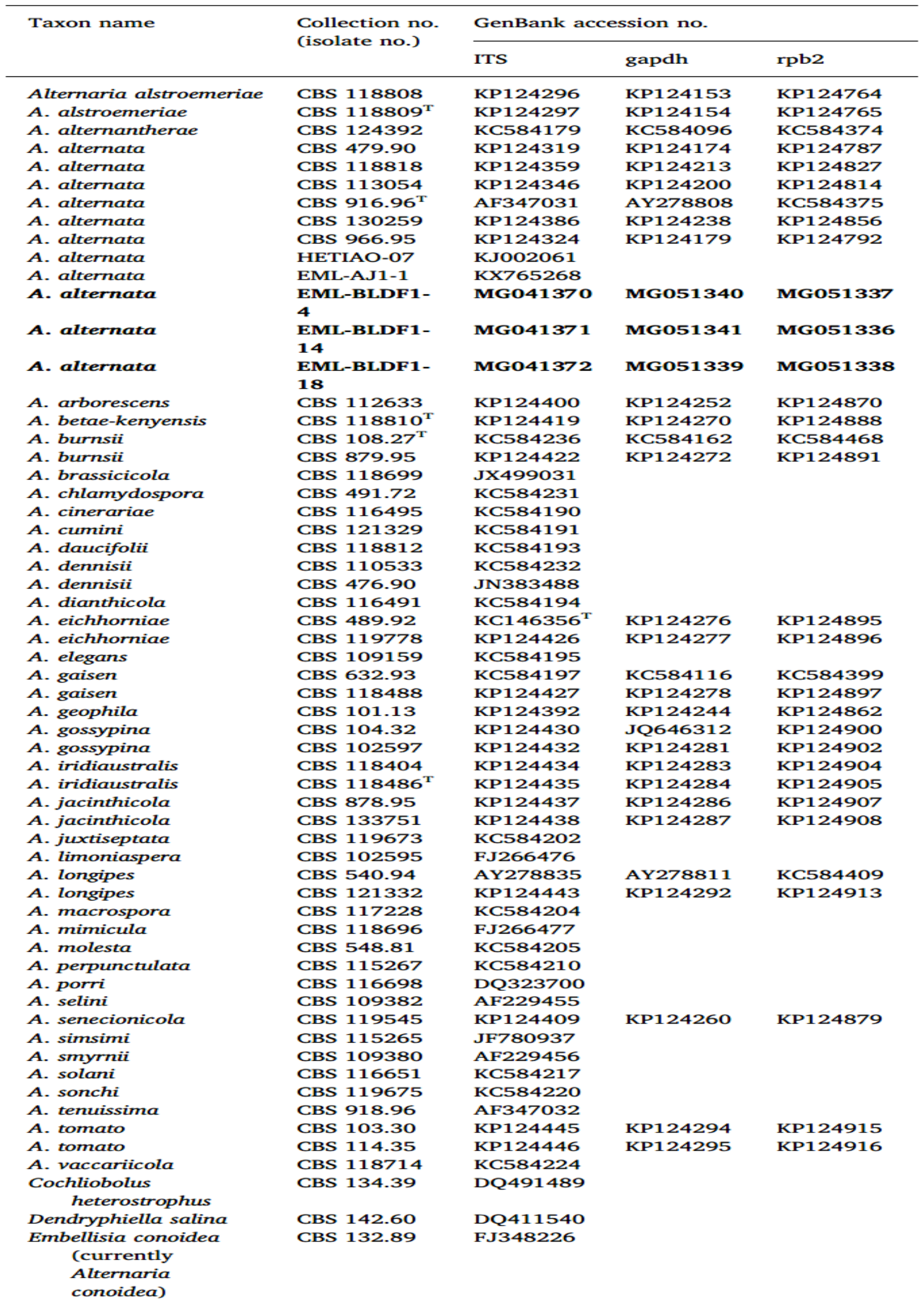


Table 1 (continued)

\begin{tabular}{lllll}
\hline Taxon name & $\begin{array}{l}\text { Collection no. } \\
\text { (isolate no.) }\end{array}$ & \multicolumn{2}{l}{ GenBank accession no. } & \\
\cline { 3 - 4 } \cline { 3 - 4 } & & ITS & gapdh & rpb2 \\
\hline $\begin{array}{c}\text { E. didymospora } \\
\text { (currently }\end{array}$ & CBS 766.79 & FJ357312 & \\
$\begin{array}{c}\text { Alternaria } \\
\text { didymospora })\end{array}$ & & & \\
E. eureka & CBS 193.86 & JN383490 & \\
\hline
\end{tabular}

CBS, Centraalbureau voor Schimmelcultures, Utrecht, The Netherlands; EML, Environmental Microbiology Laboratory Fungarium, Chonnam National University, Gwangju, South Korea; T, ex-type strain. Bold letters indicate isolates and accession numbers determined in our study.

Table 2

\begin{tabular}{|c|c|c|c|c|c|c|c|}
\hline \multirow[t]{2}{*}{ Na. } & \multirow[t]{2}{*}{ Taka } & \multirow[t]{2}{*}{ troblase no. } & \multicolumn{5}{|c|}{ Maccosesin prodtactaba" } \\
\hline & & & Ant & Atx- $t$ & $\operatorname{Tex}$ & Noet & Antr \\
\hline $\mathbf{z}$ & Alsernerta diermata & zate-numor-a & +- & +- & $\mathrm{ND}$ & -- & $+\infty$ \\
\hline$z$ & A. Dremata & tats-stova-2 & $+\infty$ & $\mathrm{ND}$ & $\mathbf{N B}$ & ++ & +- \\
\hline 3 & A. Clermasa & tutz-suson-4 & + & +- & -- & ++ & + \\
\hline 4 & A. Difernasa & tats-suros-s & ++ & +- & $\mathrm{ND}$ & $-\cdots$ & + \\
\hline 3 & A. Clemasa & tats-nunate & + & + & + & $-\cdots$ & +- \\
\hline e & A. Diternasa & tats-sunga-s & + & + & + & -- & +- \\
\hline 7 & A. eltermata & Ext-21001-0 & +4 & + & $\mathrm{ND}$ & ++ & +4 \\
\hline$=$ & A. alrernasa & zats-25:DO1-20 & + & +- & $\mathrm{ND}$ & + & + \\
\hline$\circ$ & A. eliernasa & Este-sing 1-21 & + & + & $\mathrm{ND}$ & -- & $\mathrm{ND}$ \\
\hline 20 & A. eltermasa & zatz-ntDon-2z & +- & + & - & -- & + \\
\hline 22 & A. Siermasa & Est-2tDon-2x & +- & + & - & -- & + \\
\hline $2 z$ & A. Dlernasa & Eut:-25:DO-24 & + & +- & $\mathrm{ND}$ & ++ & $+\infty$ \\
\hline 23 & A. eliernasa & Est-21:Don-2s & +- & + & - & - & +- \\
\hline 24 & A. Ditemasa & Eut:-21Da1-26 & +4 & $\mathrm{ND}$ & $\mathrm{NB}$ & ++ & $+\cdots$ \\
\hline 25 & A. Diemasa & 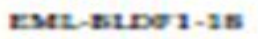 & + & $\mathrm{ND}$ & + & + & $\mathrm{ND}$ \\
\hline 20 & A. Difermata & Est-21:Den-22 & + & $\mathrm{ND}$ & $\mathrm{ND}$ & ++ & + \\
\hline 27 & A. elternasa & rats-25xsi-2 & $+\infty$ & $+\infty$ & + & ++ & $+\infty$ \\
\hline $2 \mathbf{s}$ & A. elternasa & 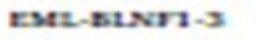 & ++ & $\mathrm{ND}$ & $\mathrm{ND}$ & ++ & ++ \\
\hline 20 & A. Diternata & tatz-5iNat-s & + & +- & + & ++ & +4 \\
\hline 20 & A. Divernasa & 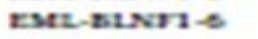 & + & + & $\mathrm{ND}$ & + & +- \\
\hline 28 & A. elremasa & Eatz-Bungats & $+\infty$ & $\mathrm{ND}$ & $\mathrm{ND}$ & ++ & +- \\
\hline 22 & A. Diemasa & tatz-nuNar-o & + & +- & $\mathrm{ND}$ & ++ & +- \\
\hline 23 & A. alermasa & 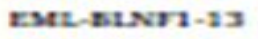 & ++ & + & $\mathrm{NB}$ & ++ & $+\infty$ \\
\hline 24 & A. Diternasa & 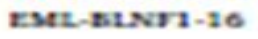 & +- & + & $\mathrm{ND}$ & ++ & $+\infty$ \\
\hline
\end{tabular}

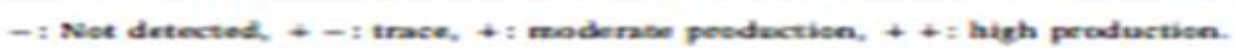

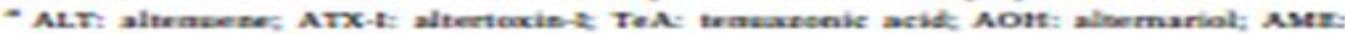
altwernasied moacenethyl edher. 
Table 3.

Optimined LC-ME/MS inatrumental parameten.

\begin{tabular}{|c|c|c|c|c|c|c|c|c|c|}
\hline Analyte" & Netertian tiae (ain) & Molkcular weight & $\operatorname{Magl}^{\prime \prime}(\mathrm{m} / \mathrm{x}, \mathrm{peaitive})$ & $\mathrm{b} p$ & $\mathrm{rp}$ & $w$ & $\mathrm{CEP}$ & $a$ & $\operatorname{CXD}$ \\
\hline \multirow[t]{2}{*}{ ALT } & 13.00 & 202.2 & $2932 \rightarrow 257.0(0)$ & 11.0 & 360.0 & 6.5 & 15.5S & 120 & 120 \\
\hline & & & $293.2 \rightarrow 200.3$ (n) & & & & & & \\
\hline \multirow[t]{2}{*}{ ATX-I } & 13.53 & 352.3 & $3.3 .2 \rightarrow 317.1(0)$ & 151.0 & 330.0 & 10.5 & 17.35 & 320 & 6.0 \\
\hline & & & 포.2 $\rightarrow 334.9$ (f) & & & & & & \\
\hline \multirow[t]{2}{*}{ TeA } & 1298 & 167.2 & $195.0 \rightarrow 124.5(0)$ & 16.0 & 270.0 & 11.3 & 65.0 & 310 & 44.0 \\
\hline & & & $198.0 \rightarrow 138.5$ (i) & & & & & & \\
\hline \multirow[t]{2}{*}{ AOH } & 13.95 & 283.2 & $20.2 \rightarrow 213.1(0)$ & 40.0 & 370.0 & 10.5 & 15.00 & 350 & 320 \\
\hline & & & $200.2 \rightarrow 217.2$ (f) & & & & & & \\
\hline \multirow[t]{2}{*}{ AME. } & 13.37 & 272.2 & $273.1 \rightarrow 257.9(0)$ & 41.0 & 270.0 & 4.0 & 13.35 & 440 & 520 \\
\hline & & & $273.1 \rightarrow 200.0(1)$ & & & & & & \\
\hline
\end{tabular}

" AL.T: albaume; ATX-1: alterisxin-1; TeA: beruazaic acid; AOHE alarnariat; AME: atumarial mazamethyl ether.

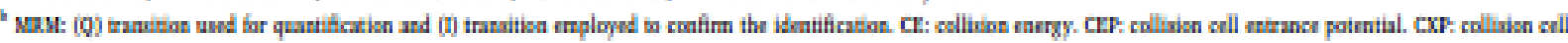

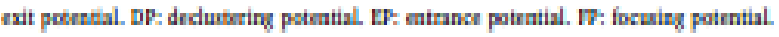

Table 4

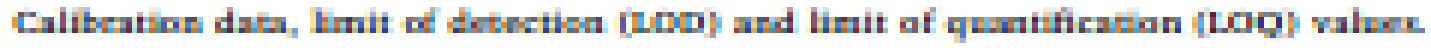

\begin{tabular}{|c|c|c|c|c|c|}
\hline Anshte & 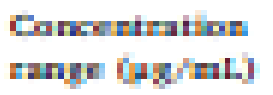 & Calibmenr muinr & $\begin{array}{l}\text { Combebn } \\
\text { frem a }\end{array}$ & $\begin{array}{l}\text { Lax } \\
\text { |mprat }\end{array}$ & $\begin{array}{l}\text { Itgd } \\
\text { ight }\end{array}$ \\
\hline ALT & a:z-1 & $Y=1137 x+14$ & DPrH4 & 113 & 1.74 \\
\hline MTNI & a-204 & $\mathrm{x}-01335 \mathrm{x}-495 \mathrm{~T}$ & Dmpa & 40 & S.D \\
\hline $\operatorname{Tn}$ & 0.215-100 & $\mathrm{Y}$ - 1TIns - 47.32 & Dpprt & 113 & 6.14 \\
\hline A매 & $4-4$ & $\mathrm{Y}-2 \mathrm{~B} 1 \mathrm{x}+\mathrm{275}$ & 5pru1 & 20 & 4.5 \\
\hline Ame & $4-04$ & Y w doth + 24p.th & Dpral & 포 & 4.5 \\
\hline
\end{tabular}

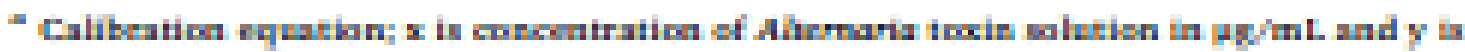
pask arat.

Table 5

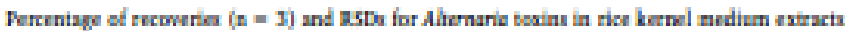

\begin{tabular}{|c|c|c|c|c|c|c|c|c|c|c|}
\hline \multirow[t]{2}{*}{ Spike levela } & \multicolumn{2}{|l|}{ ALT } & \multicolumn{2}{|l|}{ ATX-I } & \multicolumn{2}{|l|}{ TeA } & \multicolumn{2}{|l|}{ MDH } & \multicolumn{2}{|l|}{ MME } \\
\hline & Mecavery (aean, N) & nSD (N) & Recwerry (mean, N) & nso (N) & Decevery (mean, w) & ESD (N) & Mecsvery (mean, N) & 2SD (N) & Decevery (mean, w) & ESD (N) \\
\hline $1 \times 100$ & 98.2 & 5.13 & $\omega .2$ & 0.73 & 94.5 & 3.03 & 94.6 & 4.75 & 870 & 12.06 \\
\hline $2 \times 100$ & 95. 9 & 4.02 & 53.5 & E. 16 & $\boldsymbol{s . 0}$ & 3.71 & 97.7 & 0.57 & 97.7 & 0.50 \\
\hline
\end{tabular}


Table 6

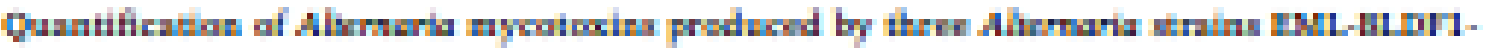

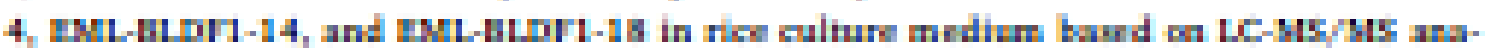
hwis.

\begin{tabular}{|c|c|c|c|c|c|}
\hline \multirow[t]{2}{*}{ Stmin } & \multicolumn{5}{|c|}{ 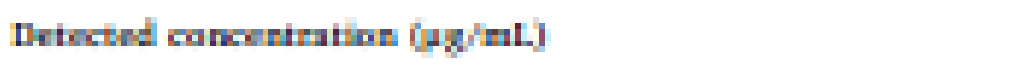 } \\
\hline & MLT & MTX-1 & Math & AHE & Tall \\
\hline MHL-14DII-4 & mes & 20.1 & EIE & 31.E & $\mathrm{ND}^{\prime \prime}$ \\
\hline BML-ILII-14 & sin & MD & 4.16 & 0.5as & $\mathrm{MD}$ \\
\hline BHL-MIT-19 & 14.5 & MD & MD & ND & 2010 \\
\hline
\end{tabular}

- MD; not drincind. 